\title{
A TRAVESSIA FACILITADA
}

Marcelo Aflalo

\section{RESUMO}

O simples ato de atravessar um obstáculo urbano, nas grandes cidades brasileiras, exige um esforço desnecessário e traz riscos para os cidadãos. As grandes avenidas, rios, linhas férreas e outras grandes fissuras urbanas são parcamente atravessadas por pontes desenhadas exclusivamente para o trânsito motorizado, sem levar em conta o pedestre ou o ciclista. As estruturas dominantes são desprovidas de valores estéticos e drenam a identidade das cidades, subtraindo a qualidade da paisagem. Esse texto apresenta uma proposta de requalificação desses equipamentos.

\section{Palavras-chave}

Travessias. Pontes Leves. Reaproveitamento de Estruturas. Madeira. 


\section{EASING THE CROSSING}

Marcelo Aflalo

\section{ABSTRACT}

The sole act of crossing an urban obstacle at a major Brazilian city requires unnecessary effort and risk for its citizens. Great avenues, rivers, train tracks and other urban cracks are barely served by bridges designed to serve motorized traffic without considering pedestrians and cyclists. Generic structures are dominant and carry no identity or aesthetical values and subtract the quality of the landscape from its viewers and users. This text leads to a proposal of the redesign and reuse of such equipment.

\section{Palavras-chave}

Crossing. Light Bridges. Reuse of Existing Structures. Timber. 


\section{INTRODUÇÃO}

Atravessar rios e avenidas de fluxo intenso e rápido, linhas de trem e demais obstáculos do traçado urbano não é tarefa fácil para o pedestre nos grandes centros urbanos. Na maioria das cidades brasileiras, o que é um direito do cidadão se apresenta como uma concessão secundária da administração pública e do desenho urbano.

A convivência entre diferentes modais de transporte pressupõe uma educação social rara, cuja falta hoje contrapõe usuários de tribos diferentes, adeptas de um ou de outro modo, aquecendo uma competição desigual entre os 8 milhões de motoristas habilitados (ou não) e os pedestres, alimentando o mau humor das cidades.

Transposição pressupõe deslocamento, movimento, conexão entre partes ou ao menos ligação entre dois pontos, de origem e de destino, que alimenta fluxos intermitentes.

Técnicos e gestores urbanos de São Paulo sempre tiveram um tratamento avaro nesse quesito, por motivos vários, quer seja pelo custo quer seja pelo mau desenho, pelo descaso com a acessibilidade ou pelo esforço desmedido para a simples tarefa de transpor um vão livre. As passarelas de pedestres, elegantes e funcionais, podem ser contadas em uma mão em São Paulo.

A elegância da passarela Ciccillo Matarazzo (Figura 1), junto ao parque do Ibirapuera, em São Paulo, contrasta com soluções tecnicistas e inacessíveis que levam potenciais usuários a correr riscos atravessando fora das faixas de pedestres, por entre carros e motos. Ironia máxima é a passarela Marcelo Fromer, cujo nome é uma homenagem ao músico atropelado por uma moto onde hoje encontra-se a passarela. De difícil acesso, a passarela continua sendo subutilizada pela grande massa de trabalhadores dos escritórios do denso bairro da Vila Olímpia.

Figura 1.

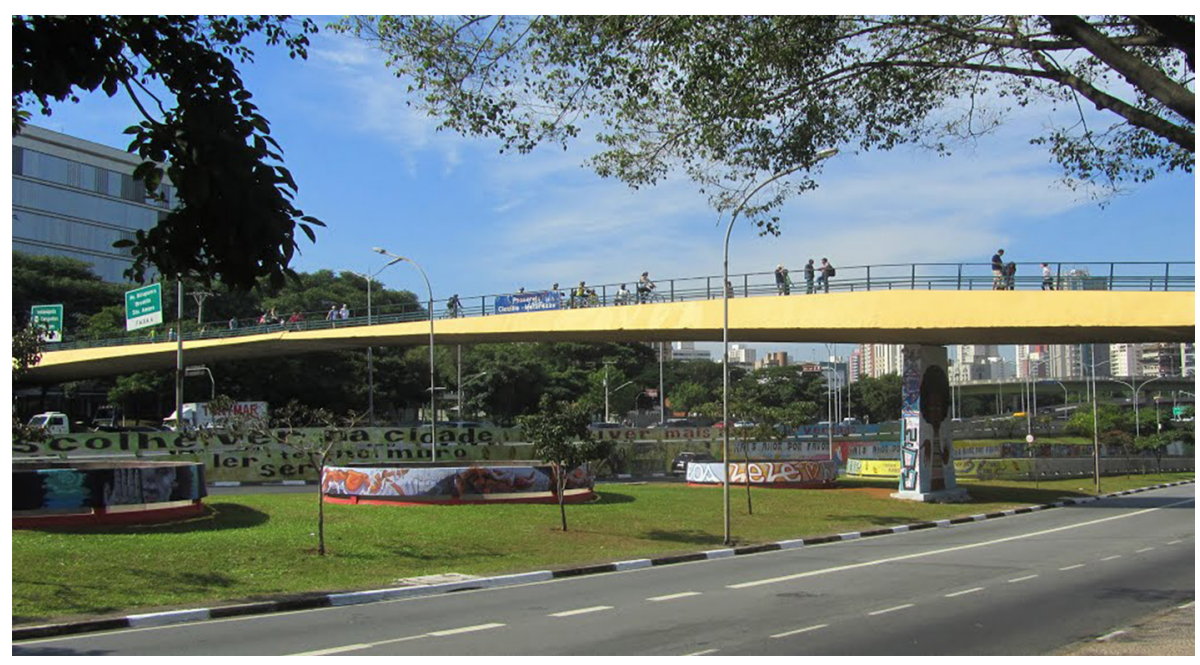




\section{MERAS TRANSFORMAÇÕES NOTÁVEIS}

Atributos abstratos aparentemente não fazem parte do léxico dos gestores urbanos, que valorizam substratos quantificáveis pela métrica das licitações e outras formas de gerência de contratos. De certa forma, as chamadas "obras de arte" - termo que designa esse tipo de equipamento urbano, como pontes e passarelas - têm pouco a ver com a origem e a nobreza dessas estruturas, verdadeiro marcos de identidade urbana nas principais cidades do mundo, como a Ponte Vecchio, em Florença ou a Pont Neuf, em Paris.

Paris é um bom exemplo de pontes e passarelas implantadas para uso de pedestres e veículos automotores (Figura 2). Cada um desses exemplos indica seu tempo e espaço pela materialidade e desenho com que foram construídos. Em todos eles, o pedestre ou é considerado usuário com as mesmas prerrogativas dos veículos com os quais coabita ou é atendido com exclusividade, com vista privilegiada para um rio Sena despoluído e dominante na paisagem (Figura 3).

Figura 2.

Ponte Simone de Beauvoir.

Fonte: Acervo do autor
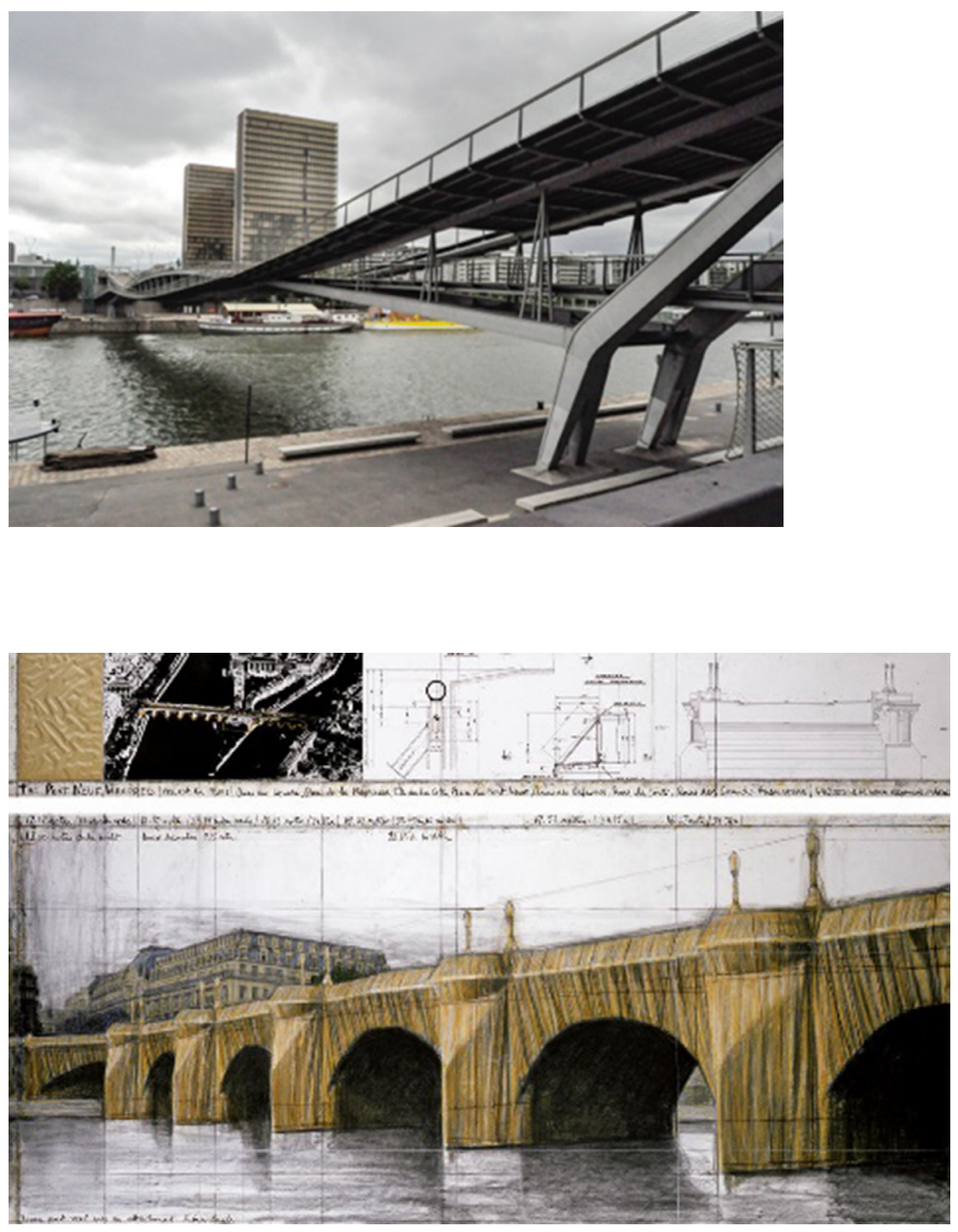

Pont Neuf, Christo e Jeanne-

Claude, 1985. Reprodução:

Wolfgang Volz. 
A Pont Neuf, de tão icônica, foi objeto de instalação dos artistas plásticos Christo e Jeanne-Claude, que ao revesti-la de tecido subtraíram uma peça importante da paisagem parisiense, consequentemente reforçando seu papel como marco referencial.

As chamadas "obras de arte" urbana têm muitas funções que extrapolam seu objeto primário de uso e, em grandes avenidas ou rios, são marcos de distância e de reconhecimento visual. Uma ponte urbana típica, não rodoviária, precisa satisfazer algumas condições de segurança e conforto, se desenhada para pedestres e veículos: estabelecer uma ligação entre duas áreas urbanas, criar um exterior atrativo, demonstrar qualidades técnicas contemporâneas e possuir uma estrutura amigável para seus usuários (SALAMAK; FROSS, 2016).

\section{MATERIALIDADE E LINGUAGEM}

A materialidade das pontes acompanhou a evolução e o domínio das diversas tecnologias adquiridas pelo conhecimento humano e, dentro dessa lógica, temos uma linha temporal e tecnológica bastante clara: madeira, pedra, metal e concreto, quando não combinando alguns ou todos esses materiais. Essa lógica começa a perder o sentido no mundo contemporâneo, justamente por conta da tecnologia e da introdução de novos conceitos que aliam questões ambientais a modelos econômicos mais racionais e eficientes. $E$, retomando o ciclo histórico do domínio da tecnologia, a madeira vem ganhando proeminência nos desenhos desses equipamentos. Por que madeira? Basicamente porque é o único material renovável em toda a cadeia construtiva, consumindo pouca energia na sua transformação e sequestrando dióxido de carbono em sua massa, com resultados inversamente proporcionais aos gerados pela produção do concreto e da indústria metalúrgica, responsáveis por maior geração de CO2 na atmosfera global.

Desde o Protocolo de Kyoto, as nações europeias, principalmente, incrementaram novas tecnologias e intensificaram o uso da madeira para atender as metas propostas pelo documento. Ao contrário da percepção popular, a renovação florestal e a plantação intensiva colaboram enormemente na maior produção de oxigênio e no sequestro do $\mathrm{CO} 2$, uma vez que é durante o crescimento que as árvores de grande porte são mais eficientes nesse processo. O manejo sustentável das florestas nativas rejuvenesce o ciclo florestal, e as plantações industriais combinadas com a agricultura permitem ciclos econômicos mais justos e ecologicamente mais adequados. Essa prática foi preconizada em 1990 por um grupo de cientistas liderados pelo geógrafo Aziz Ab'Saber, no premiado projeto Floram (Revista Estudos Avançados, USP 4/9). 
As florestas industriais representam hoje apenas 1,5\% de toda a área florestal do Brasil e são primariamente destinadas à indústria de celulose, com uma ínfima parcela destinada à produção em serrarias, diferentemente do que ocorre na Europa, no Japão ou na Austrália.

As novas tecnologias têm como base as florestas industriais. A laminação de grandes peças em madeira, conhecida desde o início dos anos 1900, evoluiu imensamente, permitindo estruturas mais leves e resistentes que as alternativas convencionais, e em algumas aplicações com custo consideravelmente menor.

Naturalmente, a evolução não foi apenas tecnológica, mas também de desenho, com estruturas delgadas e sinuosas (Figuras 4,5 e 6) resultantes do acúmulo de conhecimento sobre o material, do aprendizado sobre como protegê-lo das intempéries, do desenvolvimento de conexões mais eficientes, tanto em madeira como em outros materiais, e sobretudo do reconhecimento dos benefícios gerados pelo uso da madeira.

Figura 4. Ponte Montmorency, Québec, 2010. Fonte: Nordic Structures.

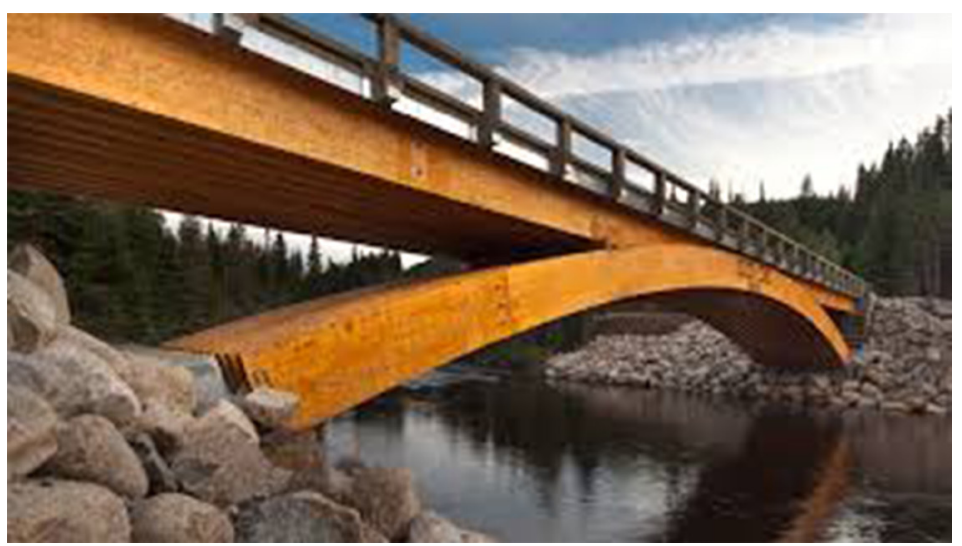

Figura 5.

Passarela em Essing, Alemanha, projetada por Richard J. Dietrich, 1986. Fonte: Brüninghoff (1993).

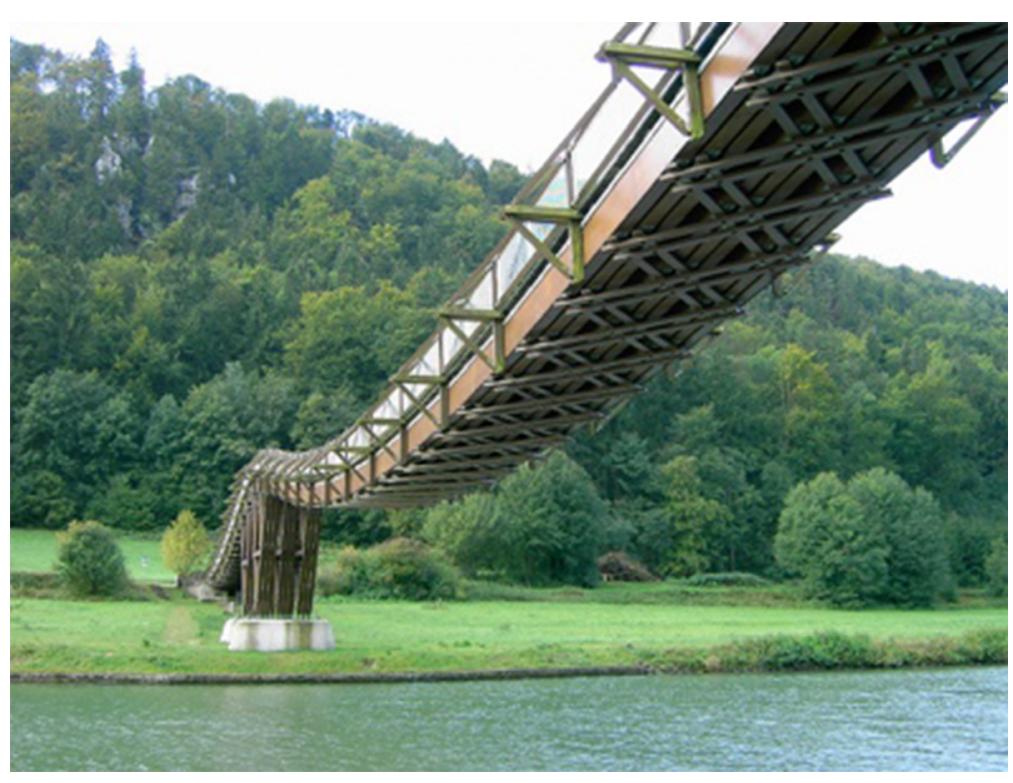


Figura 6.

Passarela em Stuttgart, 2019.

Fonte: Knippers Helbig.

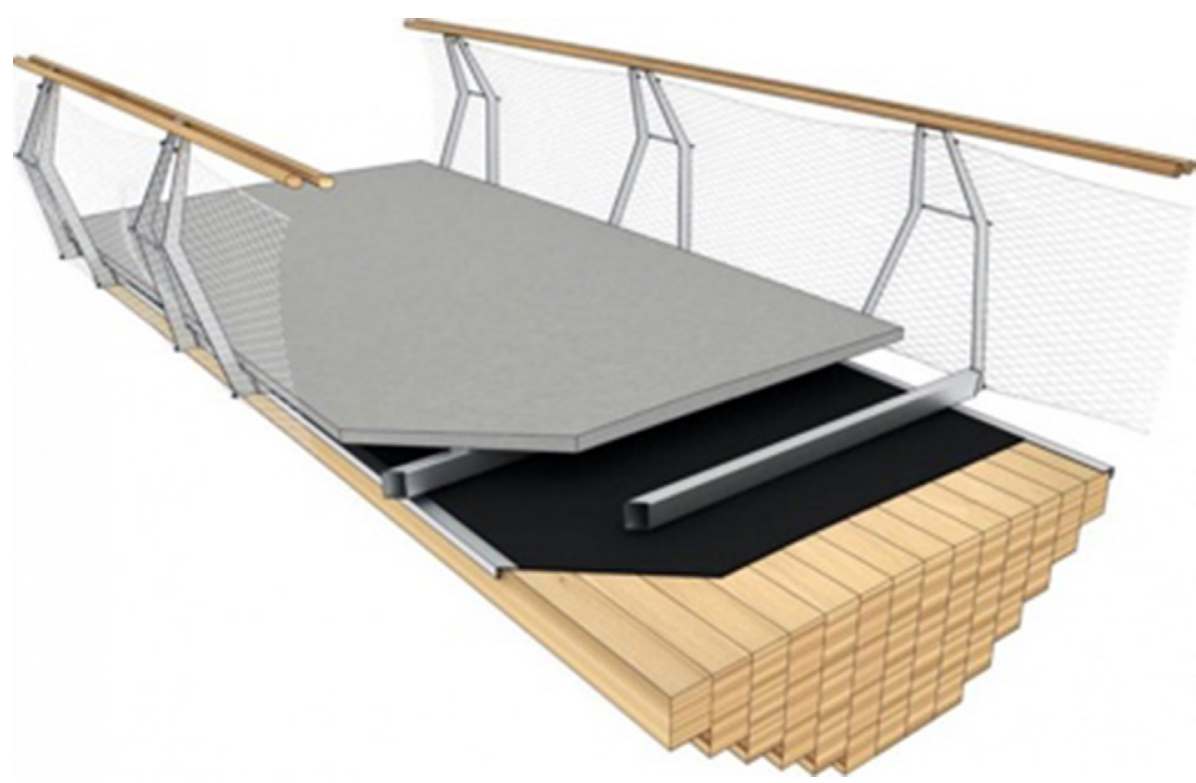

Outro grande avanço se deu com relação à escala que as novas tecnologias de laminação passaram a permitir. Vigas com 70 metros de comprimento são viáveis, embora por questões de transporte não seja simples de movimentar (NATTERER; HERZOG; VOLZ, 1994).

Esses compostos oriundos da madeira também trouxeram novos paradigmas em termos de resistência, trabalhando de forma flexível frente a movimentações sísmicas ou provocadas por vento e águas.

\section{REAPROVEITAMENTO DAS ESTRUTURAS EXIS- TENTES}

A leveza proporcionada pelos novos compostos em madeira permitiu uma possibilidade até há pouco tempo não considerada como alternativa de requalificação urbana. Grandes estruturas de concreto são demolidas para dar lugar a outras maiores, mais adequadas à ocupação e ao uso do solo, ou simplesmente pela acelerada obsolescência, tanto de desenho quanto dos materiais com que foram construídas.

O recente anúncio de uma edificação em Vancouver, projetada pelo arquiteto Shigeru Ban, abre um novo campo para a requalificação de estruturas urbanas sem a demolição da estrutura existente, diminuindo consideráveis impactos ambientais provocados pelo descarte dos resíduos e o enorme consumo de energia entre a demolição, o transporte e a reconstrução de uma nova edificação com técnicas convencionais. A edificação tem estrutura híbrida, combinando uma estrutura de concreto e outra de madeira laminada e mesclando seu uso entre habitação e áreas comerciais. Em Londres, a antiga estrutura de um 
cinema serviu como base para a construção de um pequeno prédio misto, de lazer e entretenimento (cinema e restaurante) e cinco andares residenciais, construídos em CLT e placas de madeira cruzadas e coladas, totalmente usinadas em máquinas digitais, formando uma malha estrutural que dispensa pilares e vigas durante o processo de montagem (Figuras 7 e 8 ).
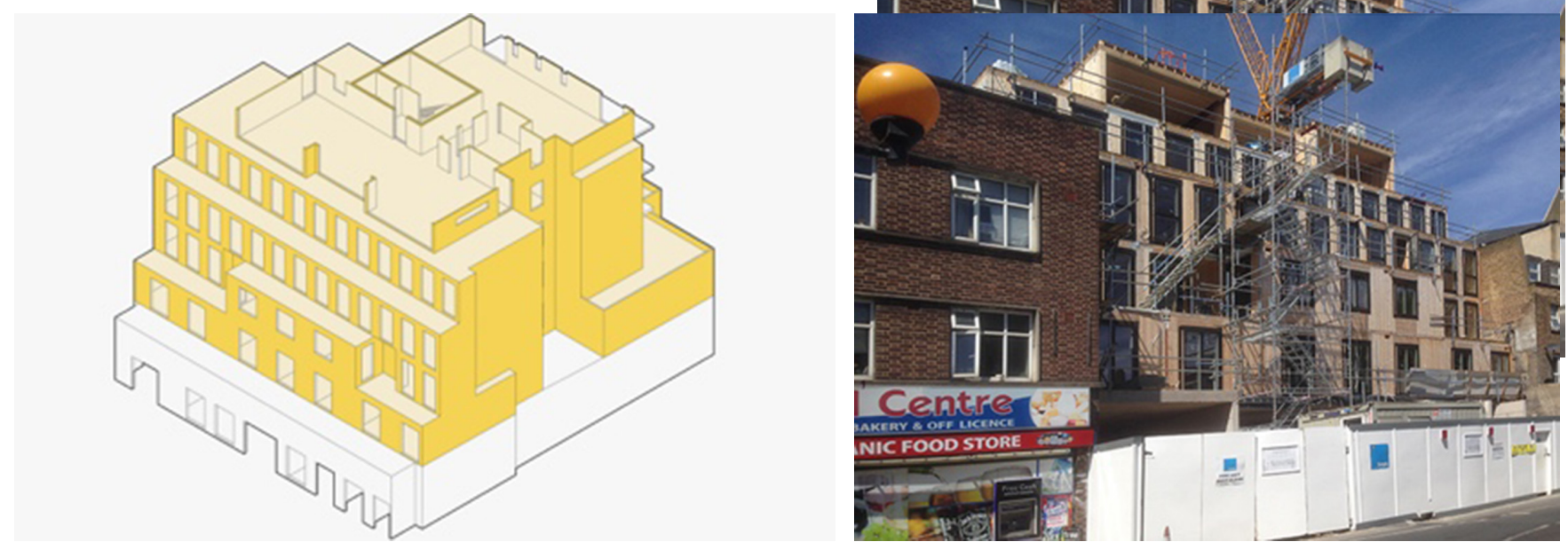

Figuras 7 e 8.

Pitfield Street, Waugh Thistleton, 2019. Fonte: Acervo do autor e Waugh Thistleton Architects.

Naturalmente, a analogia com pontes é limitada por diferenças estruturais em função do uso, da horizontalidade e da distribuição de cargas. Mesmo assim, a atitude denota uma mudança radical na leitura da paisagem construída. As construções que utilizam sistemas e materiais mistos indicam o provável futuro da construção sustentável, reduzindo o desperdício e o impacto ambiental no planeta (KAUFMANN, 2012).

Resgatar os valores perdidos ao longo de nossa recente intervenção no planeta parece ser a senda a ser trilhada, e isso inclui a liberdade de escolha formal e sua materialização dentro de valores ambientais saudáveis. Como nota Juhani Pallasmaa (2006) tanto a pobreza formal quanto o excesso vazio e o abstrato intelectualizado contribuem para o empobrecimento do significado intrínseco da arquitetura.

A industrialização de componentes e a racionalização dos processos completam o rol de atitudes projetuais a serem consideradas em qualquer campo da produção arquitetônica, uma vez que a paisagem é composta por tudo o que nos cerca, mineral, vegetal ou animal. 


\section{RECONECTANDO AS MARGENS: O CASO DA PON- TE CIDADE JARDIM}

A ponte Roberto Zuccolo, felizmente mais conhecida como Cidade Jardim, foi construída em 1967, ligando a região desenvolvida pela Cia City, nas margens do retificado Rio Pinheiros, com a região do Morumbi, próxima ao Jockey Club de São Paulo. Como todas as pontes que cruzam os grandes rios de São Paulo, foi desenhada primariamente para o uso por veículos motorizados e possui uma área mínima para travessia de pedestres ou ciclistas, em condições desfavoráveis e pouco confortáveis. Mesmo levando em conta o estado putrefato das águas dos rios paulistas, ainda assim, temos uma paisagem resiliente e um potencial de vegetação e vida animal que sinalizam uma recuperação possível a curto prazo. É, portanto, desejável que essas pontes sejam remodeladas e cumpram funções essenciais como as descritas anteriormente.

Além do equipamento em si, temos como coadjuvantes, entre os obstáculos que dificultam o uso da ponte Cidade Jardim, as alças de acesso dos automóveis que saem e chegam às marginais e a travessia de um lado ao outro da avenida sobre o tabuleiro da ponte

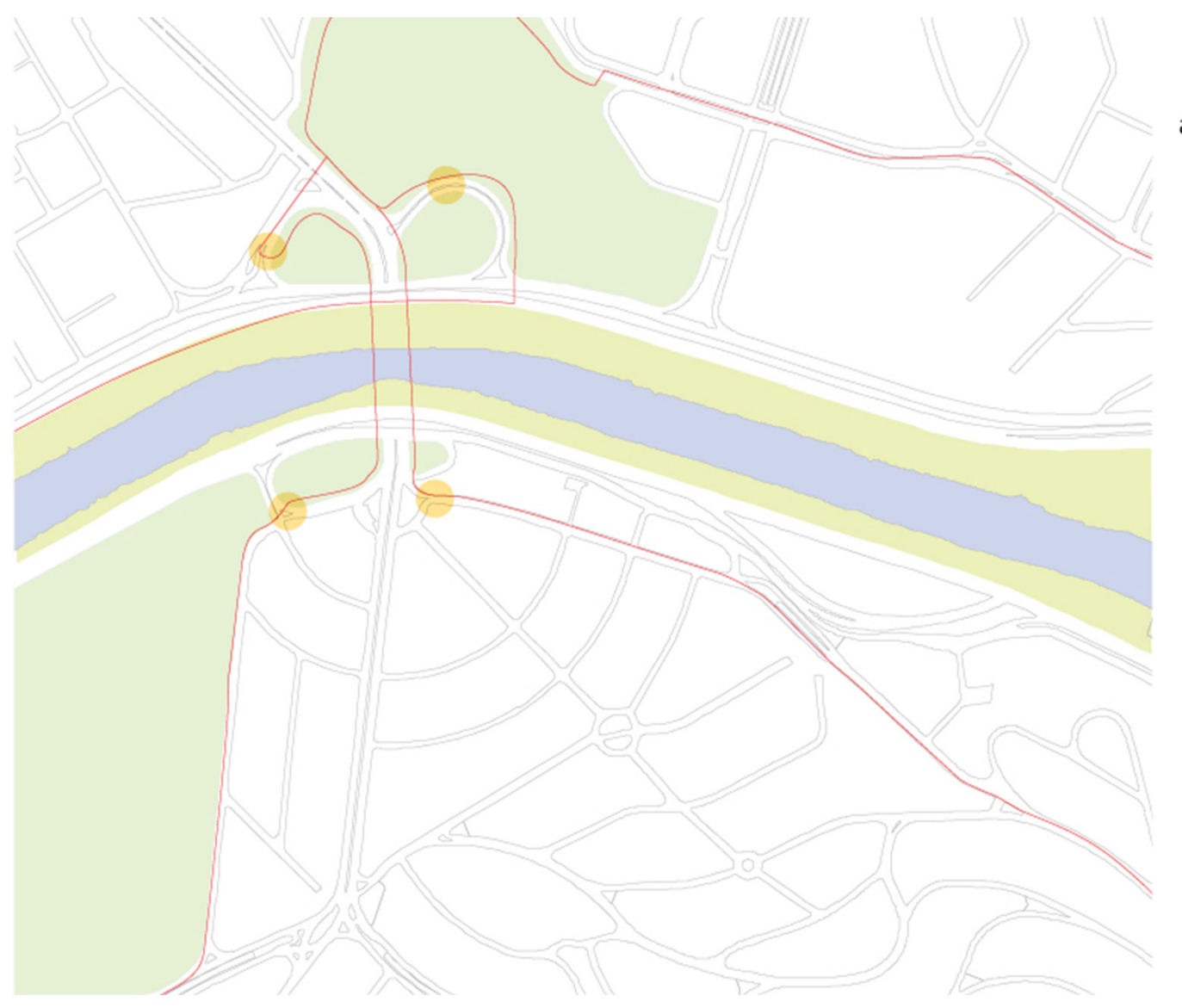

\section{ciclovia \\ áreas verdes}

rupturas

Figura 9. Mapa sem escala.

Fonte: Aflalo, 2018 
Figura 10.

Levantamento fotográfico: situação existente. Fotos de $1^{\circ}$ de julho de

2018.

(a) situação da calha existente com a separação das vias de veículos e de pedestres/ciclistas; (b) o acesso temporário da ciclovia está sendo feito por escadaria metálica; (c) as faixas de pedestre são a única forma de travessia da calha para as alças; (d) acesso parcialmente fechado em área sem faixa de pedestres; (e) acesso em rampa próximo à estação CPTM; (f) acesso em escada ou elevador junto ao Parque do Povo; (g) degraus nos acessos à calha de pedestres da ponte; (h) travessia de pedestres inexistente, com altíssimo risco junto à alça do Jockey Club. Fonte: Acervo do autor

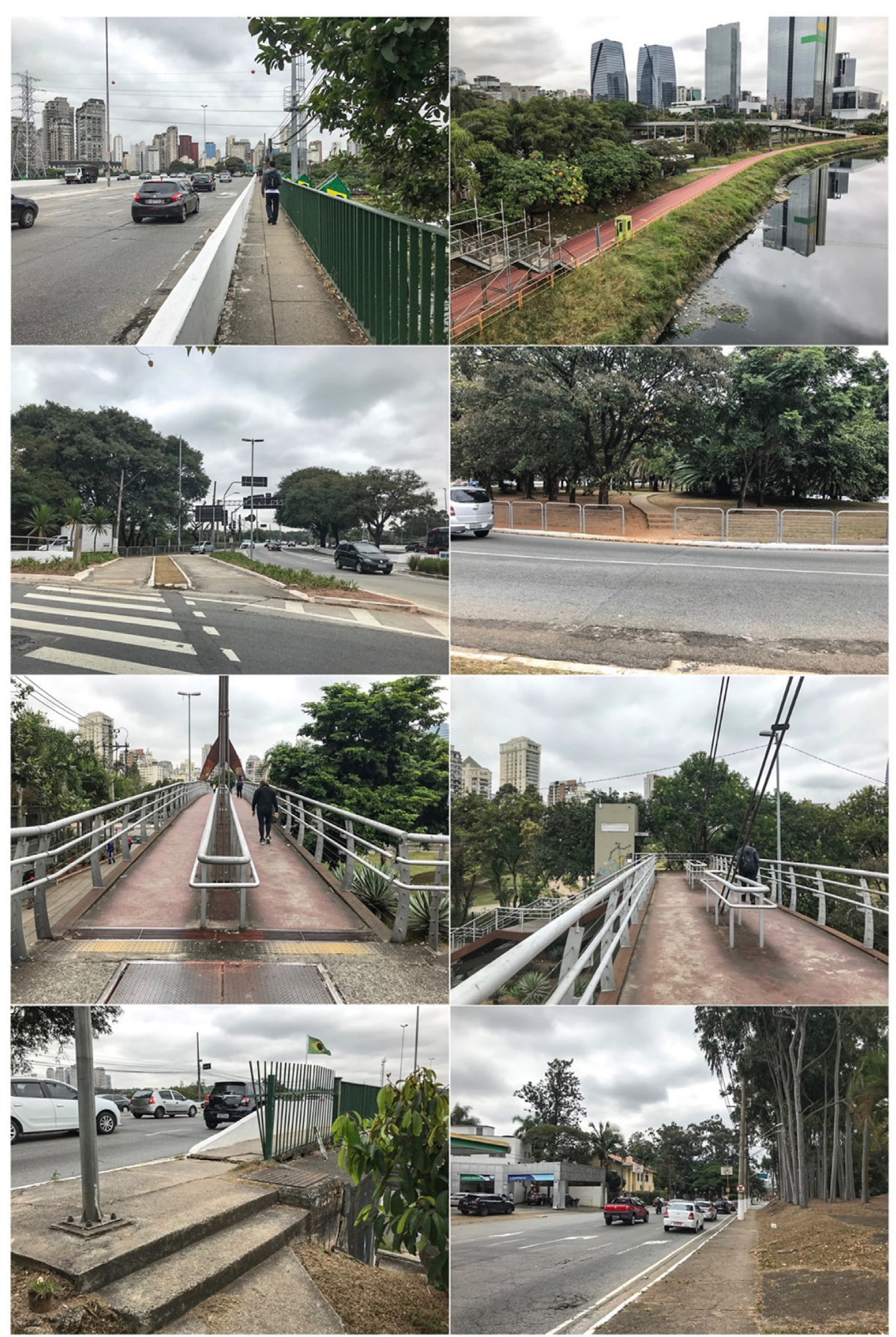

UMA PROPOSTA

Tendo como premissa a manutenção da ponte existente e o uso de materiais leves, propõe-se a criação de transposições para pedestres e ciclistas, ampliando o tabuleiro existente e conectando-o com as margens e alças do seu entorno.

As ciclovias não se conectam em condições normais, apenas em domingos e feriados, o que acontece também com o acesso de pedestres. Há uma passarela de acesso, com qualidade material e de desenho, que conecta a estação da CPTM com o Parque do Povo, mas não 
se conecta com as áreas das alças de acesso.

A adição de uma estrutura de madeira leve ao tabuleiro da ponte agrega qualidade à travessia do rio, mas não resolve a continuidade do percurso para pedestres e ciclistas. Portanto, é necessário articular essas extensões com passarelas adicionais que estabelecem a ligação entre as alças e os bairros lindeiros.

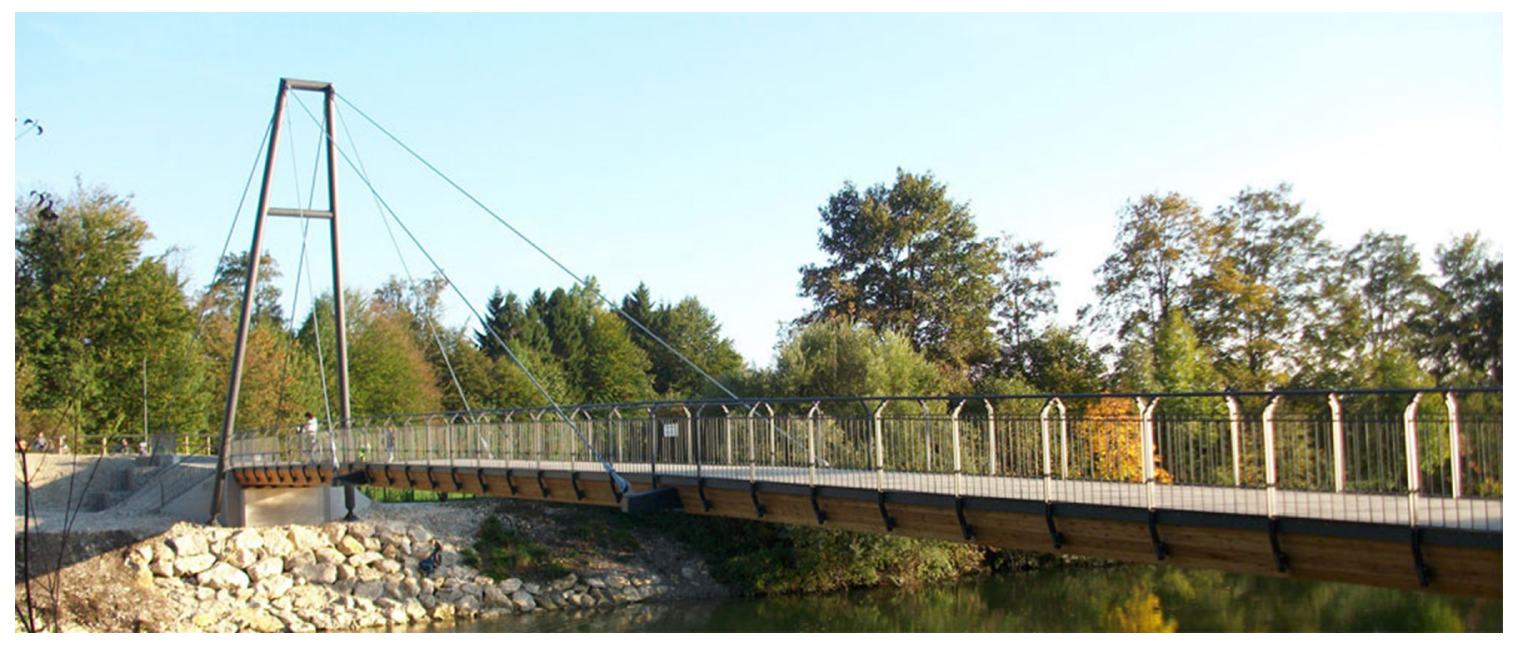

Figura 11. Passarela em Tauberbischofsheim, Alemanha, 2009.

Fonte: Miebach Engineering.

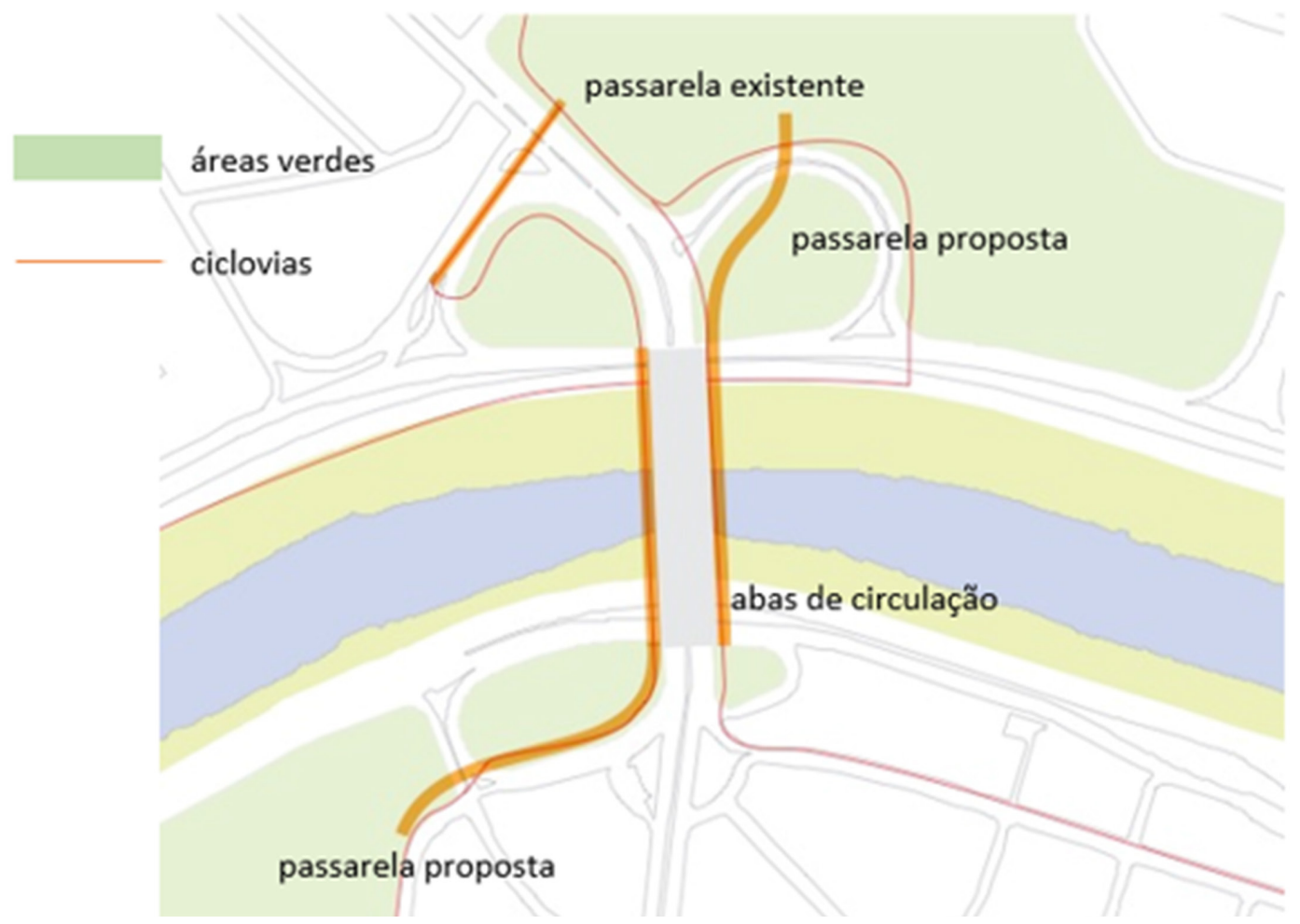

Figura 12. Mapa sem escala. Fonte: Aflalo, 2018. 
Figura13.

Ilustração sem escala. Fonte: Aflalo, 2018.

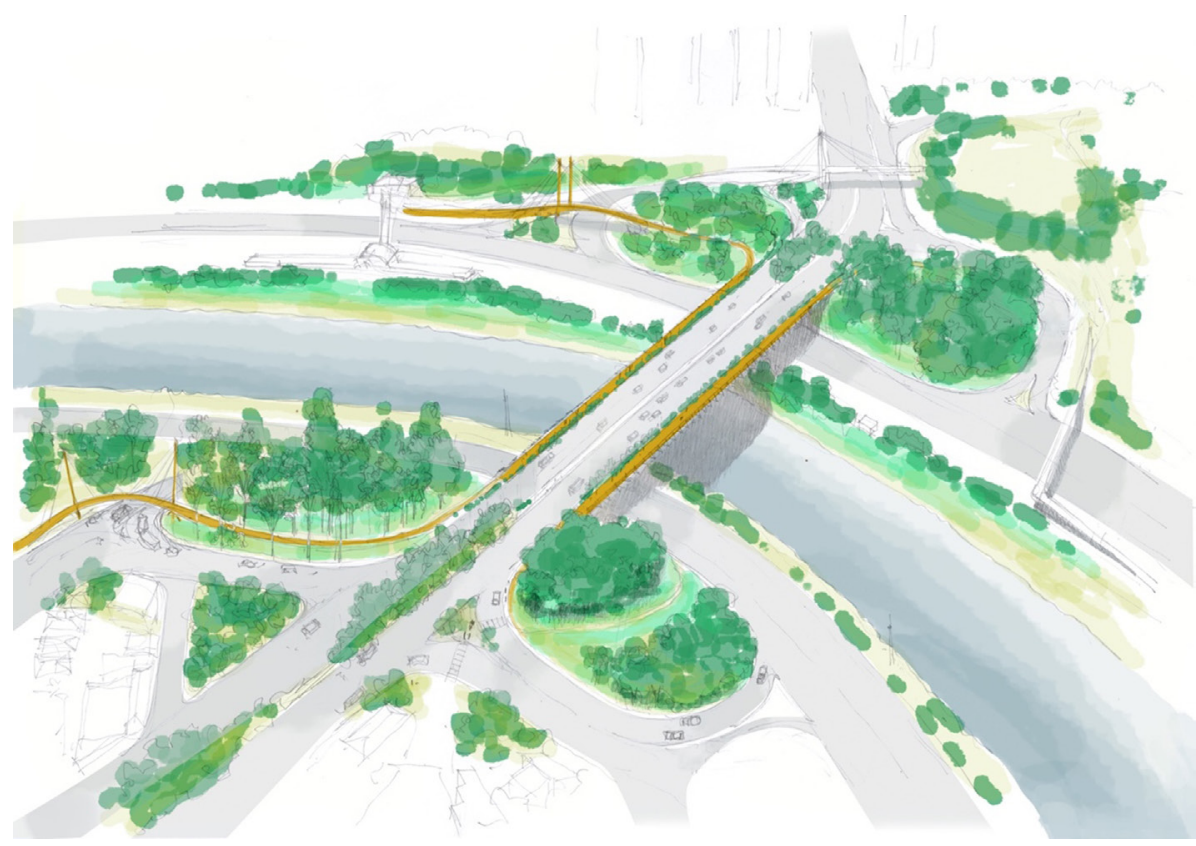

A continuidade da travessia é também a continuidade da paisagem, e isso inclui a vegetação e o mobiliário urbano, que podem ser inseridos nas obras de arte propostas.

A calha hoje destinada aos pedestres e ciclistas passa a ser uma calha verde, atenuando o impacto gerado pelo trânsito no tabuleiro existente. A iluminação passa a ter um papel fundamental, expandindo o tempo de uso com segurança e desenhando a paisagem das pontes com elementos marcantes de dia e de noite (Figura 14).

O modelo pode ser replicado, com variações, na maioria das pontes existentes em São Paulo, que podem se beneficiar de acessibilidade, marcação referencial urbana e, em última instância, identidade.

Figura 14. Corte transversal ponte Cidade Jardim. Fonte: Aflalo, 2018. 


\section{Figura 15.}

Estudo em corte sugerindo sistema construtivo com proteção/ sombreamento em bambu, sem escala. Fonte: Aflalo, 2018.

Figura 16.

Corte isométrico com a indicação do uso da calha de pedestres existente como buffer entre a pista de rolagem e a passarela, sem escala. Fonte: Aflalo, 2018.
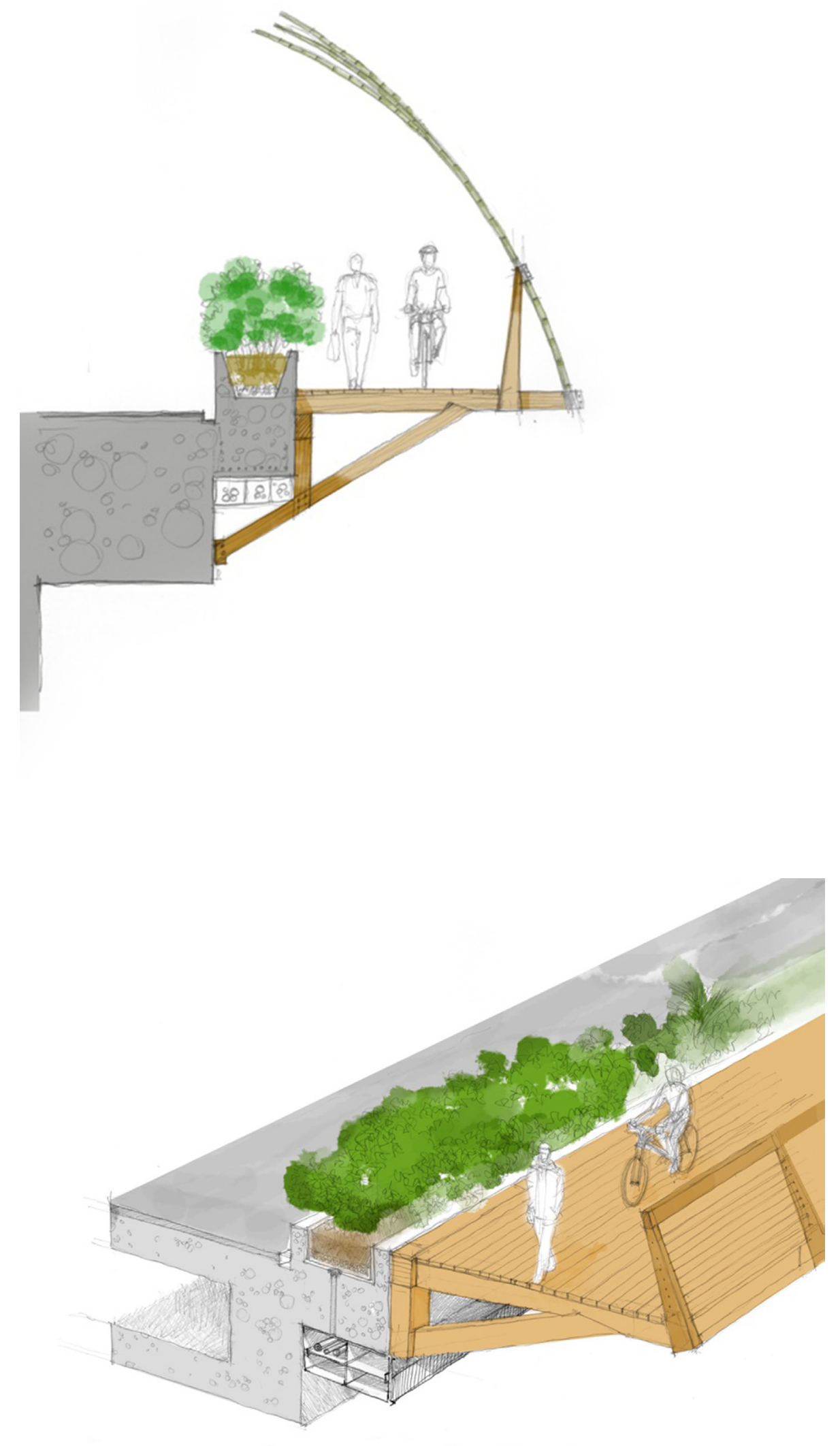
Para as passarelas que ligam as alças de acesso ao viaduto, a configuração topográfica permite uma movimentação de terra mínima para criar calhas de fluxo de trânsito sem a necessidade de uma estrutura muito alta ou muito arqueada, que dificultaria a acessibilidade. A exemplo da passarela Zapallar, próxima a Santiago, projetada por Enrique Browne, uma estrutura leve e parcialmente pré-montada, a transposição pode ser feita com mínimo impacto urbano (Figura 17).

Figura 17.

Passarela Zapallar, Chile. Fonte: Acervo do autor.

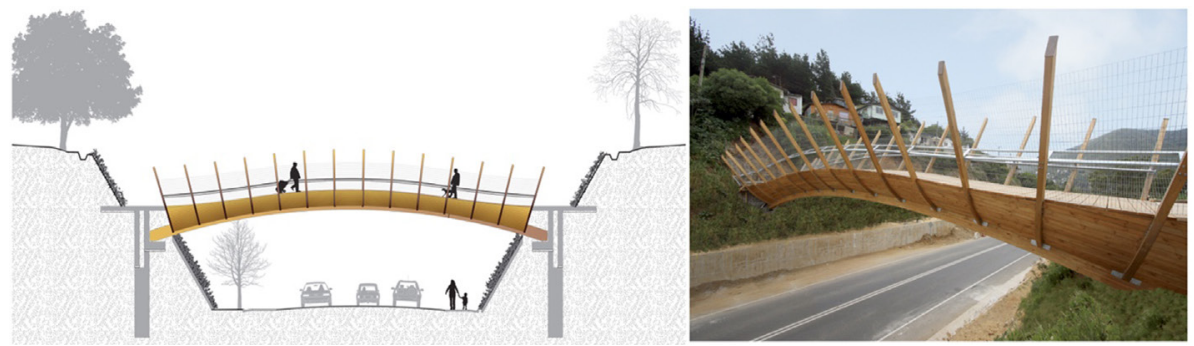

No modelo proposto, as passarelas podem ser pré-montadas e instaladas no local com interrupção do fluxo por menos de seis horas. Um eixo estrutural é apoiado em esperas de concreto armado e suspenso em um eixo central estaiado por quatro pilares ancorados nas extremidades da estrutura (Figuras 18 e 19).

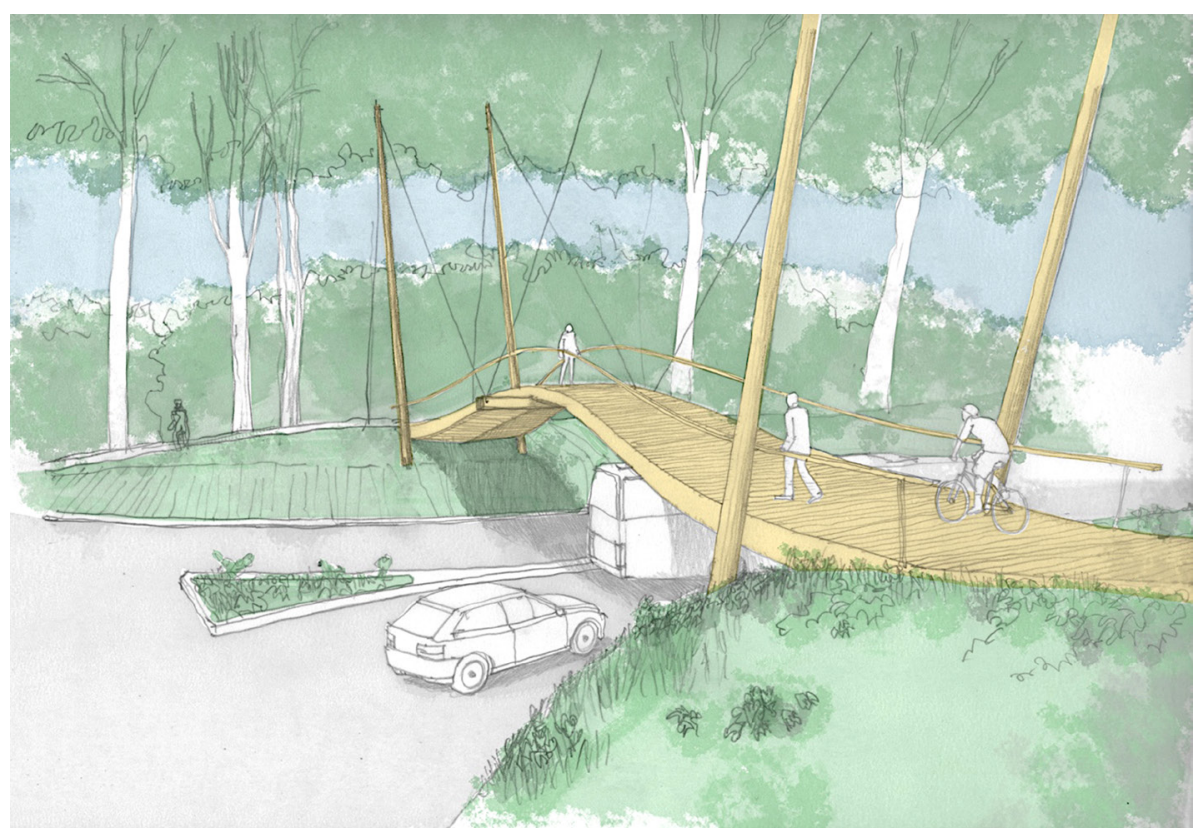




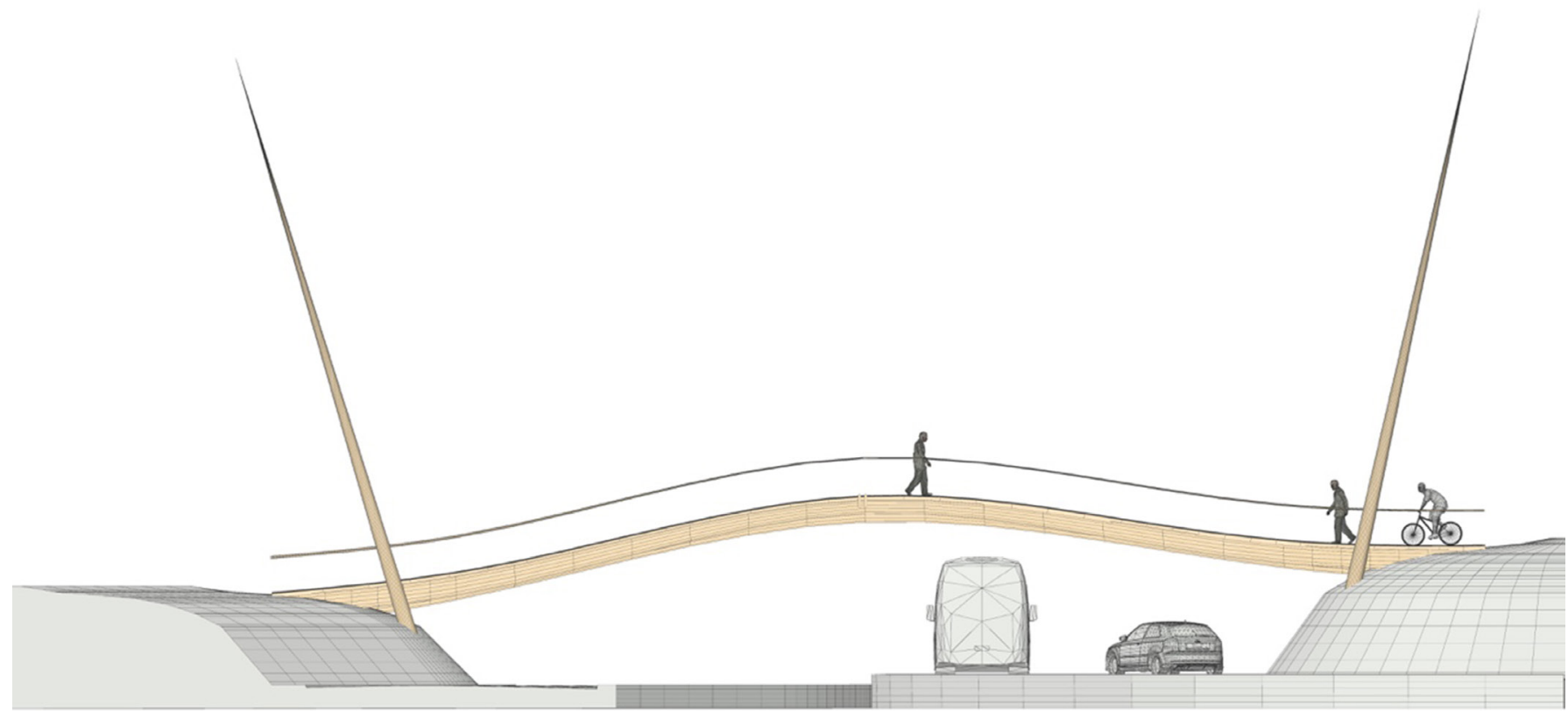

Figura 19.

Elevação lateral esquemática, sem escala. Fonte: Aflalo, 2018.

A arquitetura da madeira pressupõe um detalhamento específico para evitar o acúmulo da água, portanto todas as peças têm pequenas inclinações, vãos entre as peças e proteção sobre as partes estruturais (Figura 20).

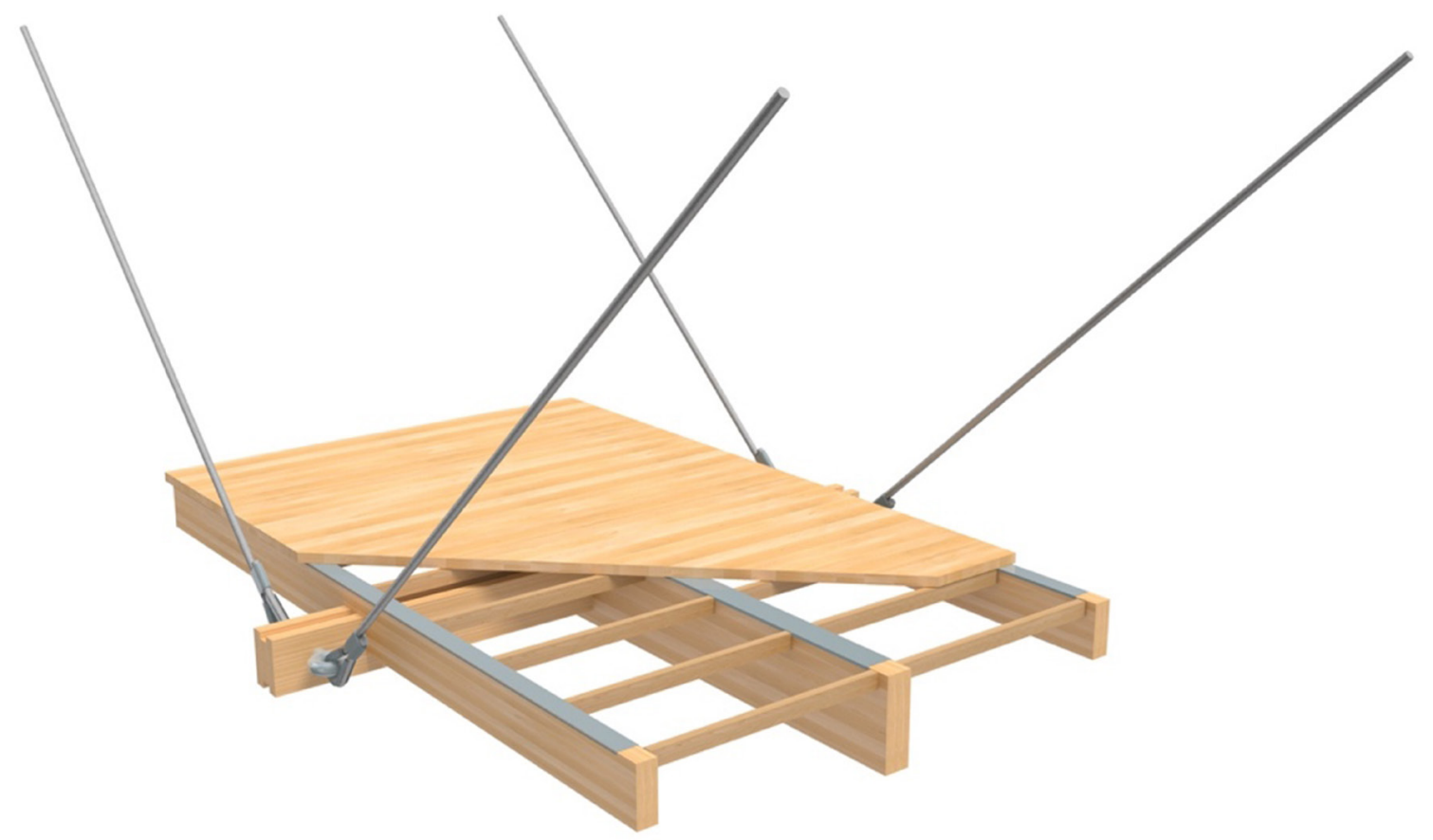

Figura 20. Detalhe construtivo. Fonte: Aflalo, 2018. 
Muito se discute sobre o uso da madeira em obras de arte urbanas, mas a realidade é que o concreto tem se mostrado muito aquém da perenidade prometida, por várias razões que não cabem nesse texto, cujo foco é apontar alternativas viáveis ao aproveitamento de equipamentos urbanos.

A madeira, por outro lado, é muito conhecida e sabe-se de sua vida útil há séculos, com equipamentos espalhados pelo mundo em operação há mais de duzentos, trezentos anos.

Por que não investigar sua viabilidade?

\section{Marcelo Aflalo}

Arquiteto e Urbanista. Docente da Fundação Armando Álvares Penteado (FAAP).

marcelo@univers.com.br

ORCID: https://orcid.org/0000-0002-3240-3272 


\section{REFERÊNCIAS}

BRÜNINGHOFF, Heinz. The Essing timber bridge, Germany. Structural Engineering International, Zurich, v. 3, n. 2, p. 70$72,1993$.

GAUZIN-MÜLLER, D. Arquitetura ecológica. São Paulo: Editora Senac, 2011.

HERZOG, T. et al. Timber construction manual. Lausanne: Presses Polytechniques et Universitaires Romandes, 2007.

KAUFMANN, H. (Ed.). Building with timber: paths into the future. München: Prestel, 2012.

MAYO, J. Solid wood: case studies in mass timber architecture, technology and design. New York: Routledge, 2015.

MENGES, A.; SCHWINN, T; KRIEG, O. D. Advancing wood architecture: a computational approach. New York: Routledge. 2017

NATTERER, J. HERZOG, T.; VOLZ, M. Construire en bois 2. Lausanne: Presses Polytechniques et Universitaire Romandes, 1994.

PALLASMAA, J. A geometria do sentimento: o olhar sobre a fenomenologia da arquitetura. In: NESBITT, K (Org.). Uma nova agenda para a arquitetura: antologia teórica (1965-1995). São Paulo: Cosac Naify, 2006.

PROJETO Floram. Instituto de Estudos Avançados da Universidade de São Paulo, São Paulo, 2013. Disponível em: http:// www. iea.usp.br/revista/assuntos/projeto-floram. Acesso em: 24 set. 2019.

ROSS, P.; DOWNES, G.; LAWRENCE, A. Timber in contemporary architecture: a designer's guide. London: RIBA, 2009.

SALAMAK M.; FROSS, K. Bridges in urban planning and architectural culture. Procedia Engineering, Amsterdam, v. 161, p. 207-212, 2016. 